\title{
Structural Characteristics, Rheological Properties, and Antioxidant Activity of Novel Polysaccharides from "Deer Tripe Mushroom"
}

\author{
Hewen Hu $\mathbb{D}^{1,2}$ Xu Teng, ${ }^{1,3}$ Shanshan Zhang, ${ }^{1,4}$ Tingting Liu, ${ }^{1,2}$ Xiao Li, ${ }^{1}$ \\ and Dawei Wang iD 1,4 \\ ${ }^{1}$ School of Food Science and Engineering, Jilin Agricultural University, Changchun 130118, China \\ ${ }^{2}$ Scientific Research Base of Edible Mushroom Processing Technology Integration of Ministry of Agriculture and Rural Affairs, \\ Changchun 130118, China \\ ${ }^{3}$ Key Laboratory of Technological Innovations for Grain Deep-Processing and High-Effeciency \\ Utilization of By-Products of Jilin Province, Changchun 130118, China \\ ${ }^{4}$ Engineering Research Center of Grain Deep-Processing and High-Effeciency Utilization of Jilin Province, \\ Changchun 130118, China
}

Correspondence should be addressed to Dawei Wang; wangdawei@jlau.edu.cn

Received 6 August 2021; Accepted 16 September 2021; Published 15 October 2021

Academic Editor: Changyang Ma

Copyright (c) 2021 Hewen Hu et al. This is an open access article distributed under the Creative Commons Attribution License, which permits unrestricted use, distribution, and reproduction in any medium, provided the original work is properly cited.

The polysaccharide was extracted by water extraction and alcohol precipitation method from "deer tripe mushroom," which was domesticated and bred from wild Auricularia delicata in Zambia. The structure of the deer tripe mushroom polysaccharide (DTMP) was characterized by gas chromatography-mass spectrometry (GC-MS), Fourier transform infrared spectroscopy (FT-IR), nuclear magnetic resonance spectroscopy (NMR), scanning electron microscope (SEM), and other analytical techniques. And the rheological and gel properties and antioxidant capacities of the polysaccharide were studied. The results showed that DTMP was mainly composed of mannose, fructose, glucose, and galacturonic acid, of which the galacturonic acid was the main component. By calculation, the molar ratio of mannose: fructose: glucose: galactoacid in DTMP is $0.8: 14.8: 1.0: 26.32$. The polysaccharide was mainly composed by $\alpha$-1,4-glycosidic bond. DTMP solution showed a shear-thinning (pseudoplastic) behaviour, and its pseudoplasticity was more obvious at a concentration of $2 \%$. The power law model was used to evaluate the viscosity curves of DTMP, and its viscosity and consistency indices both increased as the concentration increased, whereas both indices decreased as the concentration decreased. The viscosity of the polysaccharide solution changed as the $\mathrm{pH}$ changed: the polysaccharide solutions had a higher viscosity at $\mathrm{pH}=10$. DTMP showed gel-like behaviour $\left(\mathrm{G}^{\prime}>\mathrm{G}^{\prime \prime}\right)$, and the gel strength enhanced with the increase of concentration $(2 \%-10 \%)$. In addition, the antioxidant experiment of DTMP showed that it had good antioxidant activity, and there was a significant dose-effect relationship between its activity and concentration in the low concentration range.

\section{Introduction}

"Deer tripe mushroom" is a new species of edible mushroom which is domesticated and bred from wild Auricularia delicata collected in Zambia. As is known to all, Auricularia delicata is an important traditional edible and medicinal mushroom in China, India, Southeast Asia, and Congo and Cote d'Ivoire in Africa. Its medicinal effects have been reported in recent years. It is used to treat various gastrointestinal and liver diseases, and has the functions of antioxidation, antivirus, liver protection, detoxification, and treatment of gastrointestinal diseases [1]. Many types of Auricularia are rich in protein, crude fiber, vitamins, minerals, and other nutrients, and have high edible value [2-4]. A large number of studies reported that black Auricularia polysaccharide separation and other compounds, extract the medicinal properties and pharmacological activities, including fall blood sugar, fall hematic fat 
and cholesterol, anti-inflammatory, antioxidation, antitumor, antivirus, immune regulation, etc. [5-9]. Polysaccharide is the main active component in Auricularia. However, compared with polysaccharides of Auricularia auricula and Auricularia cornea, which are widely cultivated in China, there are few studies on the edible value and processing properties of novel polysaccharide of deer tripe mushroom.

Rheology is the study of flow and deformation, especially the behaviour of transitions between solids and fluids [10]. Carrageenan and gellan are materials with unique rheological and gel properties, which have been widely used in the food industry. Pectin is primarily used in the food industry because of its gelling, thickening, and stability ingredient [11]. Therefore, some studies of physicochemical and rheological properties are very important and need to be further successfully developed and understood for application. In recent years, the rheological properties of polysaccharides extracted from various natural plants including mushrooms have been studied extensively $[12,13]$. In addition, with the study of structure identification and physical properties of edible fungus polysaccharide, it has been widely used in the field of food. Some edible fungus polysaccharides dissolve in water to form gels, which can be widely used as thickening agent, gelling agent, stabilizer, emulsifier, and other applications in food [14]. Xu et al. isolated a polysaccharide fraction (FMPS) from floral mushrooms cultivated in Huangshan Mountain, and the rheological properties of FMPS in aqueous solutions were investigated, which exhibited weak gel behaviour with the change of concentration and temperature [12]. Bao et al. [15] studied the rheological properties of Auricularia auricula polysaccharide and found that Auricularia auricula polysaccharide has high viscosity and the ability to form a heat stable gel, which can be used as a new hydrogel in functional foods. Zhu et al. [16] extracted $\beta$-glucan from Auricularia auricularia and prepared a novel $\beta$-glucan-based hydrogel. However, whether there are related properties of Auricularia auricularia and its domesticated deer's ear has not been reported yet.

In this study, the deer tripe mushroom polysaccharide was extracted by hot water extraction method, and the structure characterization, rheological properties, and antioxidant activity of polysaccharide were studied, in order to provide a solid foundation for the in-depth research and industrial application of polysaccharide from the deer tripe mushroom. This research provides information of DTMP that may be useful for its application in the food industry.

\section{Materials and Methods}

2.1. Materials. Deer tripe mushroom was made by the academician Li Yu Laboratory of College of Fungal Crop Science, Jilin Agricultural University. 2,2-Diphenyl-1-picrylhydrazyl (DPPH), ferrous sulfate, and trichloroacetic acid (TFA) were purchased from Shanghai McLean Biochemical Technology Co. Standard monosaccharides including, arabinose (Ara), rhamnose (Rha), galactose (Gal), glucose (Glc), xylose (Xyl), mannose (Man), fucose (Fuc), fructose (Fru), and galacturonic acid (Gala) were provided by Sigma Chemical Co. The other chemical reagents were of analytical grade and provided by Beijing Chemical Works.
2.2. Preparation of DTMP. A $10.0 \mathrm{~g}$ sample was added to $1000 \mathrm{~mL}$ of distilled water and extracted under (kept at $90^{\circ} \mathrm{C}$ or 4 hours), repeated for 2 times, after which it was filtered and centrifuged $\left(4000 \mathrm{~g}, 15 \mathrm{~min}, 4^{\circ} \mathrm{C}\right)$. The supernatant was concentrated to $1 / 3$ of the original volume, and 4 volumes of 95\% ethanol was then added, after which the mixture was stirred until precipitation completed at $4^{\circ} \mathrm{C}$ for $24 \mathrm{~h}$. Protein was removed 6 times with the Sevag method [17]. Then, the precipitate was obtained after centrifugation ( $4000 \mathrm{~g}$, $20 \mathrm{~min}$ ) and washed with 95\% ethanol (3-4 times). The DTMP was obtained after freeze drying (ALPHA, 1-2 LDplus, Marin Christ Co., Osterode, Germany). The extraction rate of DTMP extracted using hot water was $12.5 \%$.

2.3. FT-IR Analysis. The dried polysaccharide powder $(2.0 \mathrm{mg})$ was put in an agate mortar and dried $\mathrm{KBr}$ crystal $(200 \mathrm{mg})$ was added, it was evenly ground, which was pressed into tablets. It was measured using an infrared spectrometer (Bruker Optics Co., Berlin, Germany) in the range of $4000-500 \mathrm{~cm}^{-1}$.

2.4. Monosacchride Composition. The monosaccharide composition of DTMP was determined by gas chromatography-mass spectrometry (GC-MS) of Zhang et al. [18], using an 7890A-5975GC instrument (Agilent Technologies, CA, USA). The sample ( $5 \mathrm{mg}$ ) was weighed and placed in a plug tube and hydrolyzed with $2 \mathrm{~m} \mathrm{~L} 2.0 \mathrm{~mol} / \mathrm{L}-1 \mathrm{TFA}$ (trifluoroacetic acid) at $110^{\circ} \mathrm{C}$ for $3 \mathrm{~h}$. After hydrolysis, hydroxylamine hydrochloride $(10 \mathrm{mg})$, internal standard inositol hexaacetate $(2 \mathrm{mg})$, and pyridine $(0.5 \mathrm{ml})$ were added to the fully hydrolyzed sample. After uniform oscillation, the reaction was carried out in an oil bath at $90^{\circ} \mathrm{C}$ for $30 \mathrm{~min}$. After cooling, acetic anhydride $(0.5 \mathrm{ml})$ was added to the total hydrolyzed sample for $30 \mathrm{~min}$ at $90^{\circ} \mathrm{C}$. The saccharin acetate derivatives were dried with $\mathrm{N} 2$, then $1 \mathrm{~mL}$ methylene chloride was added to dissolve them again, and $0.2 \mu \mathrm{L}$ was used for GC analysis. Chromatographic conditions: chromatographic column: HP- $5 \mathrm{~ms} \quad(30 \mathrm{~mm} \times 0.25$ $\mathrm{mm} \times 0.25 \mathrm{um}$ ); detector: hydrogen flame ionization detector (FID); the carrier gas: $\mathrm{N} 2$; flow rate: $1.0 \mathrm{~m} / \mathrm{min}^{-1}$; program heating: $100^{\circ} \mathrm{C}$ for $2 \min -260^{\circ} \mathrm{C}\left(10^{\circ} \mathrm{C}\right.$. Min-1)$260^{\circ} \mathrm{C}$ for $3 \mathrm{~min}$; 9 monosaccharides (L-rhamnose, $\mathrm{D}$-arabinose, $\mathrm{D}$-xylose, $\mathrm{D}$-mannose, $\mathrm{D}$-glucose, $\mathrm{D}$-galactose, and so on) were treated as above.

2.5. Nuclear Magnetic Resonance (NMR) Spectroscopy. The samples were dissolved in $99.9 \% \mathrm{D}_{2} \mathrm{O}$, and the ${ }^{1} \mathrm{H}-\mathrm{NMR}$ and ${ }^{13} \mathrm{C}$ NMR spectra of the samples were determined by Bruker $400 \mathrm{MHz}$ nuclear magnetic resonance spectroscopy (Bruker, Fallanden, Switzerland).

\subsection{Rheological Properties of DTMP}

2.6.1. Preparation of DTMP Solutions. In order to accelerate the dissolution of DTMP, DTMP was added to $100 \mathrm{~mL}$ of distilled water to prepare $0.1 \%, 0.5 \%, 1 \%, 1.5 \%$, and $2 \%(\mathrm{w} / \mathrm{v})$ 
DTMP solutions followed by stirring at $50^{\circ} \mathrm{C}$ for $1 \mathrm{~h}$ with a magnetic stirrer.

2.6.2. Steady Flow Behaviour. The rheological properties of the DTMP solutions were determined using a DHR-1 Rheometer (TA Instruments, USA). A parallel plate rotor (diameter $50.0 \mathrm{~mm}$ ) with a gap of $0.104 \mathrm{~mm}$ was installed on the rheometer. Static rheology was performed allowing 2 min before testing. All measurements were taken at $25 \pm 0.1^{\circ} \mathrm{C}$, and all experiments were carried out at least in triplicate.

According to the solution fluid type, the typical formula of the curtain law model was used to describe its rheology:

$$
\eta_{s}=K \gamma^{n-1}
$$

where $\eta_{s}$ is the apparent viscosity (Pa.s), $K$ is the consistency index $\left(\mathrm{Pa} \cdot \mathrm{s}^{n}\right)$, and $n$ is the flow behaviour index. Using the solution system, rheological curve fitting was performed to obtain the rheological curve of the $K$ value and $n$ value.

(1) Determination of Flow Properties at Different Concentrations. DTMP solutions with different mass concentrations $(0.1 \%, 0.5 \%, 1.0 \%, 1.5 \%$, and $2.0 \%(\mathrm{w} / \mathrm{v}))$ were accurately prepared and incubated for $20 \mathrm{~min}$ in a $70^{\circ} \mathrm{C}$ water bath with an DHR-1 Rheometer (TA) (diameter $40.0 \mathrm{~mm}$ ). Using a spacing of $1 \mathrm{~mm}$, shear rate of $0.1-1000 \mathrm{~s}^{-1}$, and measured temperature of $25^{\circ} \mathrm{C}$, the viscosity of the solution was observed with the shear rate changes.

(2) Determination of Flow Properties at Different $p H$ Values. Before the viscosity measurements, $1.0 \%$ of the $\mathrm{pH}$ of the DTMP solution was adjusted to around 2, 4, 6, 8, or 10 using $4 \mathrm{M} \mathrm{NaOH}$ or $\mathrm{HCl}$. The temperature was also controlled at $25^{\circ} \mathrm{C}$ in a water bath, and the shear rate ranged from 0.1 to $1000 \mathrm{~s}^{-1}$.

(3) Determination of Flow Properties at Different Temperatures. According to Determination of Flow Properties at Different Concentrations, $1.0 \%$ of the DTMP solution was loaded onto the rheometer substrate using parallel plates, and the sample was allowed to sit for $1 \mathrm{~h}$ to stabilise the temperature. The experimental temperatures were $25,35,45$, 55,65 , and $75^{\circ} \mathrm{C}$. The shear rate ranged from 0.1 to $100 \mathrm{~s}^{-1}$.

2.6.3. Dynamic Viscoelasticity Tests. Dynamic viscoelasticity measurements were used to determine the storage modulus $\left(G^{\prime}\right)$ and loss modulus $\left(G^{\prime \prime}\right)$ of the DTMP solution (1.0-2.0\% $(\mathrm{w} / \mathrm{v}))$. The linear viscoelastic region of the DTMP was determined by a strain sweep ranging from 0.1 to $1000 \%$ with $1 \mathrm{~Hz}$ of frequency at $25^{\circ} \mathrm{C}$. $\mathrm{G}^{\prime}$ and $\mathrm{G}^{\prime \prime}$ were measured at a frequency sweep of $0.1-100 \mathrm{~Hz}$ at $1.0 \%$ strain.

2.7. Gel Properties Test. The polysaccharide gels with mass concentration of $2.0 \%, 4.0 \%, 6.0 \%, 8.0 \%$, and $10.0 \%(\mathrm{w} / \mathrm{v})$ were obtained. They were stored in refrigerator at $4^{\circ} \mathrm{C}$ overnight before texture analysis. The composite gels were punctured test (TA-XT Plus, StableMicro System Co., UK) with a stainless-steel plate probe $(\mathrm{P} / 5)$. The pretest speed, test speed, posttest speed, distance, and trigger force were $2.0 \mathrm{~mm} / \mathrm{s}, 1.0 \mathrm{~mm} / \mathrm{s}, 2.0 \mathrm{~mm} / \mathrm{s}, 15 \mathrm{~mm}$, and $5 \mathrm{~g}$, respectively. The maximum sustained force was the gel strength. Each sample was tested 3 times.

2.8. SEM Test. The samples were frozen at $-20^{\circ} \mathrm{C}$, which were observed through a Hitachi S3000 N scanning electron microscope (Tokyo, Japan) at an accelerating voltage of $20 \mathrm{kV}$.

2.9. Antioxidant Activity Analysis of DTMP. The DPPH radical, ABTS, hydroxyl radical, and superoxide anion radical scavenging activities of DTMP were measured as previously described [19-22].

2.10. Statistical Analysis. In this study, all experimental values were expressed as the mean of three trials \pm the standard deviation. An analysis of variance (ANOVA) was performed using Origin 2018 and SPSS20.0.

\section{Result}

\subsection{Rheological Properties of DTMP}

\subsubsection{Steady Shear Flow Behaviour}

(1) Effect of Concentration on Viscosity. Based on the curves of apparent viscosity and shear rate of different concentrations of DTMP shown in Figure 1, the different concentrations of polysaccharide solution showed typical nonNewtonian behaviour and an obvious shear-thinning area. This phenomenon has been described previously in the literature $[15,23]$. The shear thinning behaviour of the DTMP solution may be due to the fact that the macromolecules are oriented along the streamline and the open entangled structure cannot be recovered in time. As predicted, the steady shear viscosity decreased as the shear rate increased. When the concentration of DTMP increased, the shear thinning phenomenon was still observed. As expected, as the polysaccharide concentration increased, the viscosity of all polysaccharide solutions increased at certain shear rates.

As shown in Table 1, the static rheological curve could be described by the power law model. Moreover, the $K$ values increased as the concentration increased, whereas the opposite trend was observed with the $n$ values, which decreased from 0.325 to 0.164 . As shown in Table 1, the power law model was observed to be favourably applicable for the DTMP polysaccharides $\left(R^{2}>0.99\right)$, and $n$ was less than 1 , which indicated the pseudoplasticity of non-Newtonian fluid. As the concentration of the solution increased, shear thinning was indicated, and the viscosity of the solution system increased as the DTMP solution concentration increased. Lower values of $n$ were observed at higher DTMP concentrations, indicating typical pseudoplastic flow behaviours. $K$ is a systematic indicator of a sticky nature. As the DTMP concentration increased from $0.5 \%$ to $2.0 \%(\mathrm{mg} / \mathrm{mL})$, 


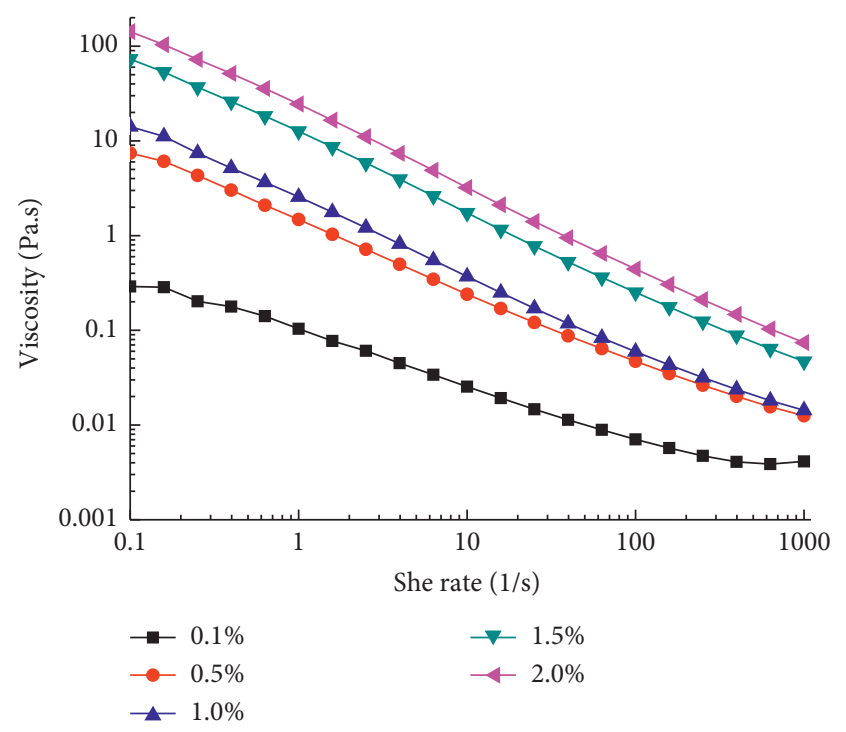

FIGURE 1: Relationship between apparent viscosity and shear rate of different concentrations of DTMP solutions.

TABLE 1: Fitting parameters for the power law model of DTMP.

\begin{tabular}{lccc}
\hline Concentration $(\%)$ & $n$ & $K\left(\mathrm{~Pa} \cdot \mathrm{s}^{n}\right)$ & $R^{2}$ \\
\hline 0.1 & $0.325 \pm 0.032$ & $1.8321 \pm 0.0222$ & 0.9955 \\
0.5 & $0.310 \pm 0.043$ & $2.0713 \pm 0.0335$ & 0.9979 \\
1.0 & $0.218 \pm 0.031$ & $2.4153 \pm 0.4041$ & 0.9958 \\
1.5 & $0.184 \pm 0.014$ & $6.5461 \pm 0.7065$ & 0.9989 \\
2.0 & $0.164 \pm 0.016$ & $7.2946 \pm 0.9083$ & 0.9998 \\
\hline
\end{tabular}

Each value represents the mean \pm standard deviation (SD) of three determinations.

$K$ increased from 1.8321 to 7.2946 . In this region, it is generally the DTMP particle-particle interactions that influence the flow behaviour of DTMP solution $[24,25]$. As the polymer concentrations increased, individual particles began to overlap to form intermolecular linkages or "connecting regions" that limited the movement and stretching of the polymer chains in aqueous solution. Therefore, the viscosity increased significantly as the polysaccharide concentration increased [26]. The results showed that the higher the concentration was, the stronger the shear-thinning, and at a high concentration, DTMP solution formed a pseudoplastic fluid. Polysaccharides extracted from other mushrooms, such as Ganoderma lucidum polysaccharides [27], also exhibit shear thinning behaviour.

(2) Effect of $p H$ on Viscosity. Figure 2 presents the curves of apparent viscosity and shear rate of a DTMP solution (1.0\%) under different $\mathrm{pH}$ conditions. The results indicated that the rheological behaviour of the DTMP solution $(10 \mathrm{mg} / \mathrm{mL})$ changed between acidic conditions ( $\mathrm{pH} 2-6)$ and alkaline conditions ( $\mathrm{pH} \mathrm{6-10).} \mathrm{The} \mathrm{shear-thinning} \mathrm{effect} \mathrm{was} \mathrm{seen}$ over the whole range of $\mathrm{pH}$ values (Figure 2). The solutions exhibited a higher viscosity at $\mathrm{pH}=10$ and a lower apparent viscosity at $\mathrm{pH}=2$ and $\mathrm{pH}=4$. Strong acids may cause the hydrolysis of polysaccharides, thereby reducing the viscosity.

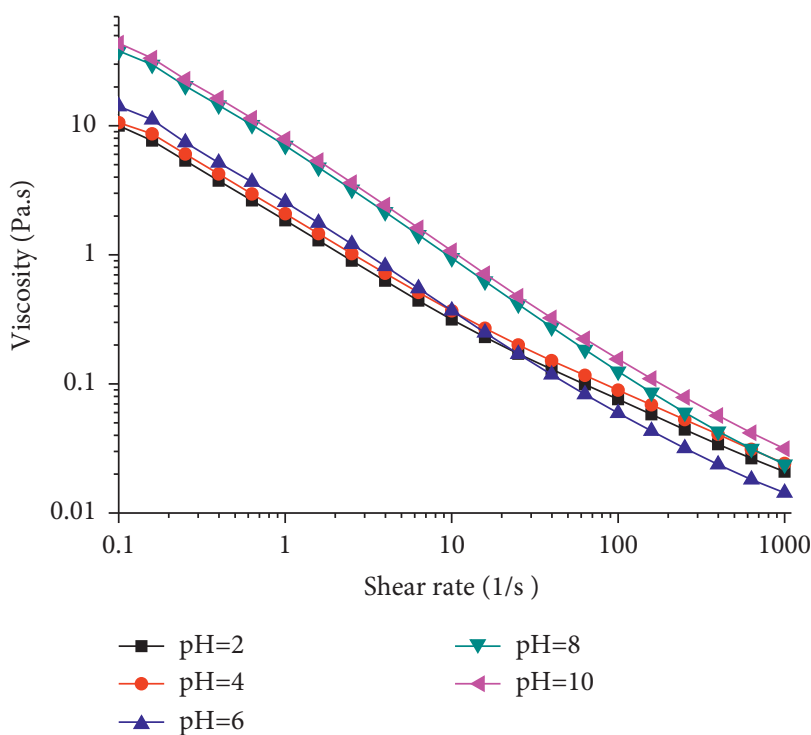

FIgURE 2: Relationship between the apparent viscosity and the shear rate of DTMP solution (1.0\%) under different $\mathrm{pH}$ values.

Conformational changes are structural changes caused by fluctuations in ion interactions or base compositions that are attributed to changes in $\mathrm{pH}$ [28]. However, this trend is different from that of Auricularia polysaccharides, in which the viscosity decreased when the $\mathrm{pH}$ became acid [15].

(3) Effect of Temperature on Viscosity. Temperature is an important factor affecting the rheological properties of fluids. Figure 3 shows the apparent viscosity curve of DTMP solution $(1.0 \%)$ at $25-75^{\circ} \mathrm{C}$. As can be seen from Figure 3, the viscosity of the solution increased with the increase of temperature. A possible reason for this trend may be that at higher temperatures, the molecular motion becomes more intense, and the molecular forces gradually stronger, which increases the molecular flow of the solution system and results in higher viscosity. However, the pseudoplastic fluid behaviour remains even at the highest temperature.

3.1.2. Dynamic Viscoelasticity. Figure 4 shows the $\mathrm{G}^{\prime}$ and $\mathrm{G}^{\prime \prime}$ data of DTMP. The DTMP is affected by both viscosity and elasticity, which can be represented using $G^{\prime}$ and $G^{\prime \prime}$. $G^{\prime}$ (storage modulus) represents the elastic component, and $\mathrm{G}^{\prime \prime}$ (loss modulus) represents the sticky component. The dynamic rheological properties of DTMP in the linear viscoelastic region were measured to ensure that the polysaccharides had not been destroyed. $G^{\prime}$ and $G^{\prime \prime}$ of DTMP were essentially constant with stresses from 0.1 to $1.0 \%$, but when strain was $>1.0 \%, \mathrm{G}^{\prime}$ and $\mathrm{G}^{\prime \prime}$ were reduced (Figure 4(a)). Thus, 1.0\% strain was selected as the dynamic viscoelasticity measurement of DTMP. The dynamic viscoelasticity measurement must appear in the linear viscoelastic region to ensure the polysaccharide structure [29]. Regardless of what happens to the concentration of DTMP, $\mathrm{G}^{\prime}$ and $\mathrm{G}^{\prime \prime}$ of both groups were enhanced with increased frequency (Figure $4(\mathrm{~b})$ ). In addition, $\mathrm{G}^{\prime}$ was always higher than $\mathrm{G}^{\prime \prime}$; the DTMP exhibited a gel-like behaviour. 


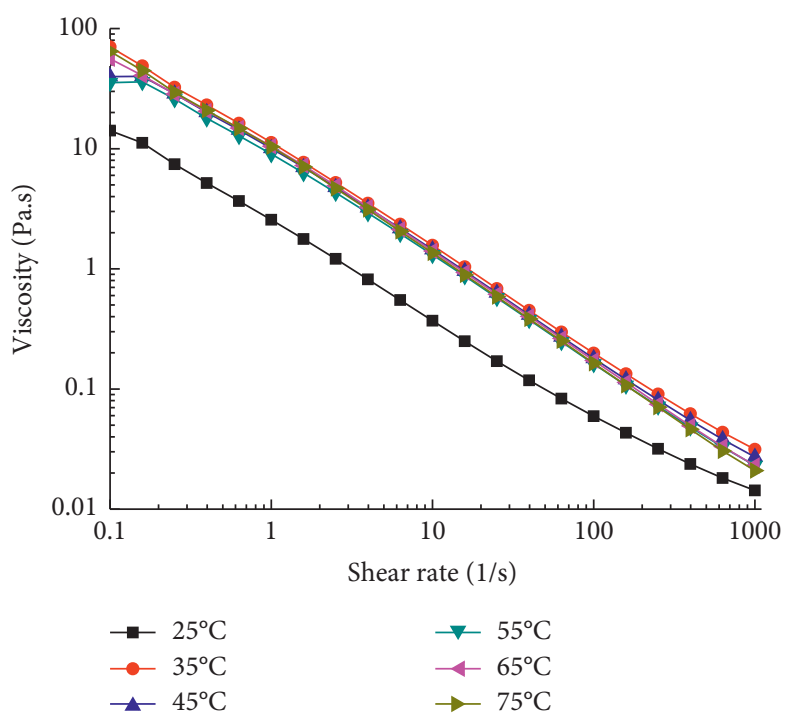

FIgURE 3: Relationship between the apparent viscosity and the shear rate of DTMP solution $(10 \mathrm{mg} / \mathrm{mL})$ at different temperatures.

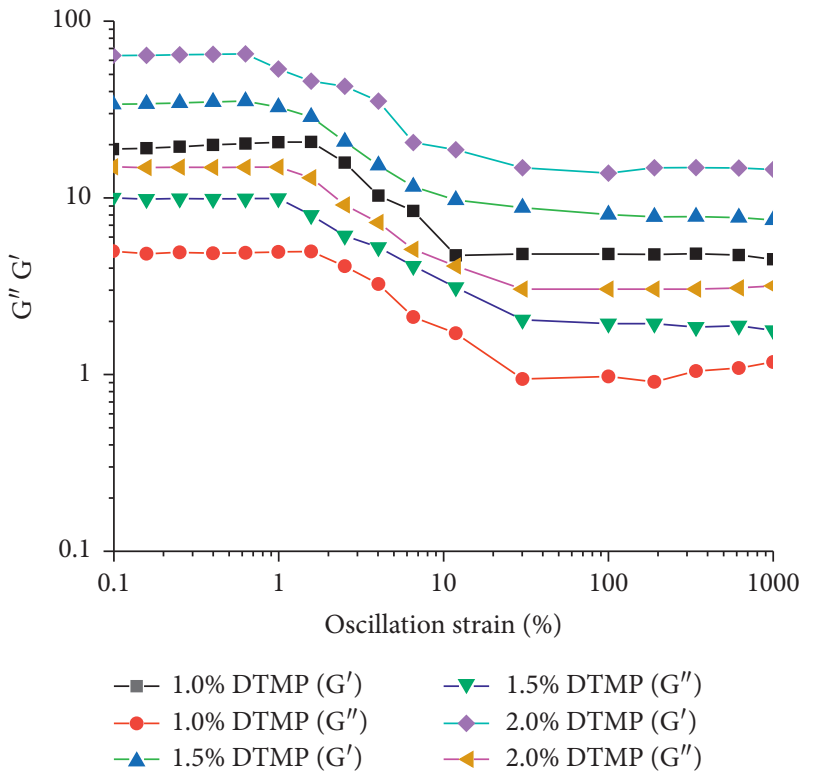

(a)

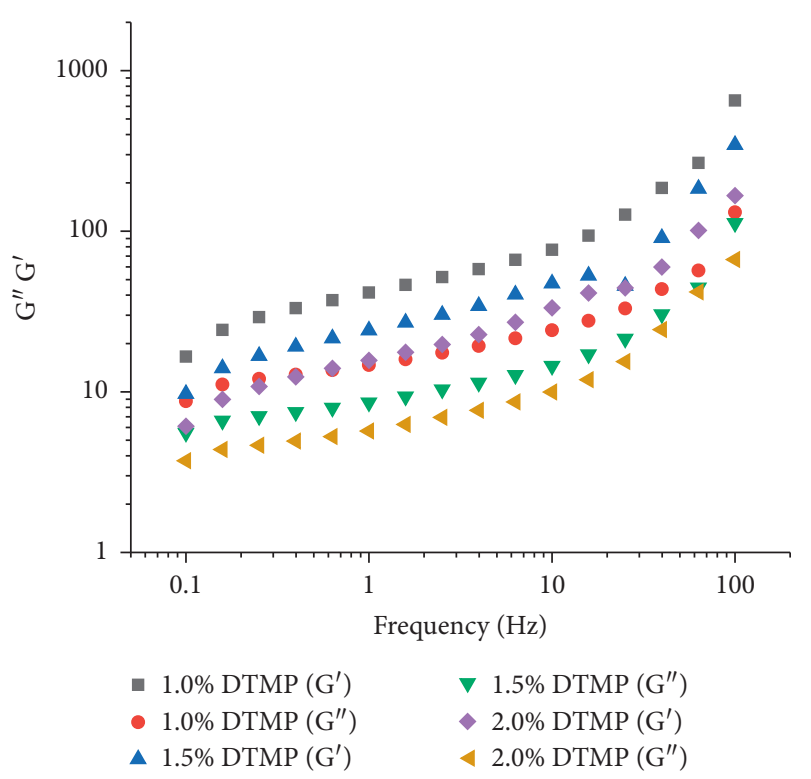

(b)

FIgURE 4: Viscoelasticity of DTMP. (a) Strain sweeps performance at $1.0 \mathrm{~Hz}$. (b) Frequency sweeps at $1 \%$ strain.

3.2. FT-IR Spectroscopy Analysis. FT-IR analysis of DTMP was carried out by $\mathrm{KBr}$ tablet pressing method, and the infrared spectrum in the range of $4000-500 \mathrm{~cm}^{-1}$ is shown in Figure 5. A wide peak was present at $3251.46 \mathrm{~cm}^{-1}$, which was caused by the stretching vibration between the polysaccharide characteristic $-\mathrm{OH}$ and the $\mathrm{O}-\mathrm{H}$ bond of water. And the absorption peak near $2918.17 \mathrm{~cm}^{-1}$ was observed $\mathrm{C}-\mathrm{H}$ stretching vibration and variable angle vibration $[25,31]$. There was a strong absorption peak at 1715.73 and $1600.56 \mathrm{~cm}^{-1}$, which was caused by the $\mathrm{C}=\mathrm{O}$ asymmetric stretching vibration, indicating that there might exist an aldehyde group -CHO. Generally, the sugar molecule-bound water was found as an absorption peak in this region [32].
The absorption peak at $1488.47 \mathrm{~cm}^{-1}$ was the variable angle vibration of $\mathrm{C}-\mathrm{H}$, and the above four are the characteristic absorption peaks of polysaccharide [33]. $1241.92 \mathrm{~cm}^{-1}$ and $1028.55 \mathrm{~cm}^{-1}$ characteristic absorption peaks indicated that DTMP contained pyran-type glycosylic bonds, and $\alpha-(1-6)$ glycosylic bonds might be existed. FT-IR results showed that DTMP might be pyran type and exhibited $\alpha$-configuration.

3.3. Monosaccharide Composition Analysis. DTMP was degraded by TFA and then derivatized with pyridine and acetic anhydride for GC-MS analysis. Figure 6 shows the monosaccharide composition of strandards and DTMP. As could 


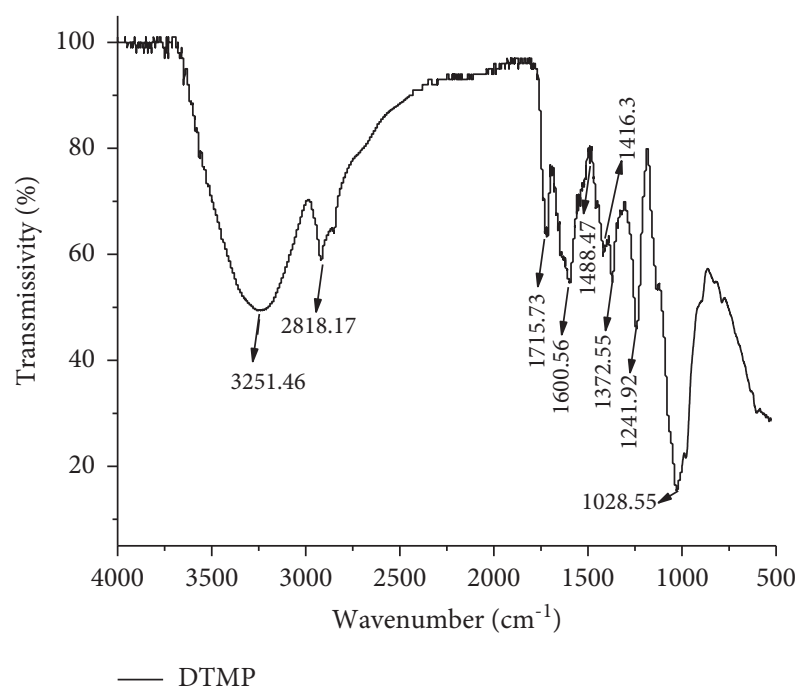

FIGURE 5: Fourier infrared spectra of DTMP.
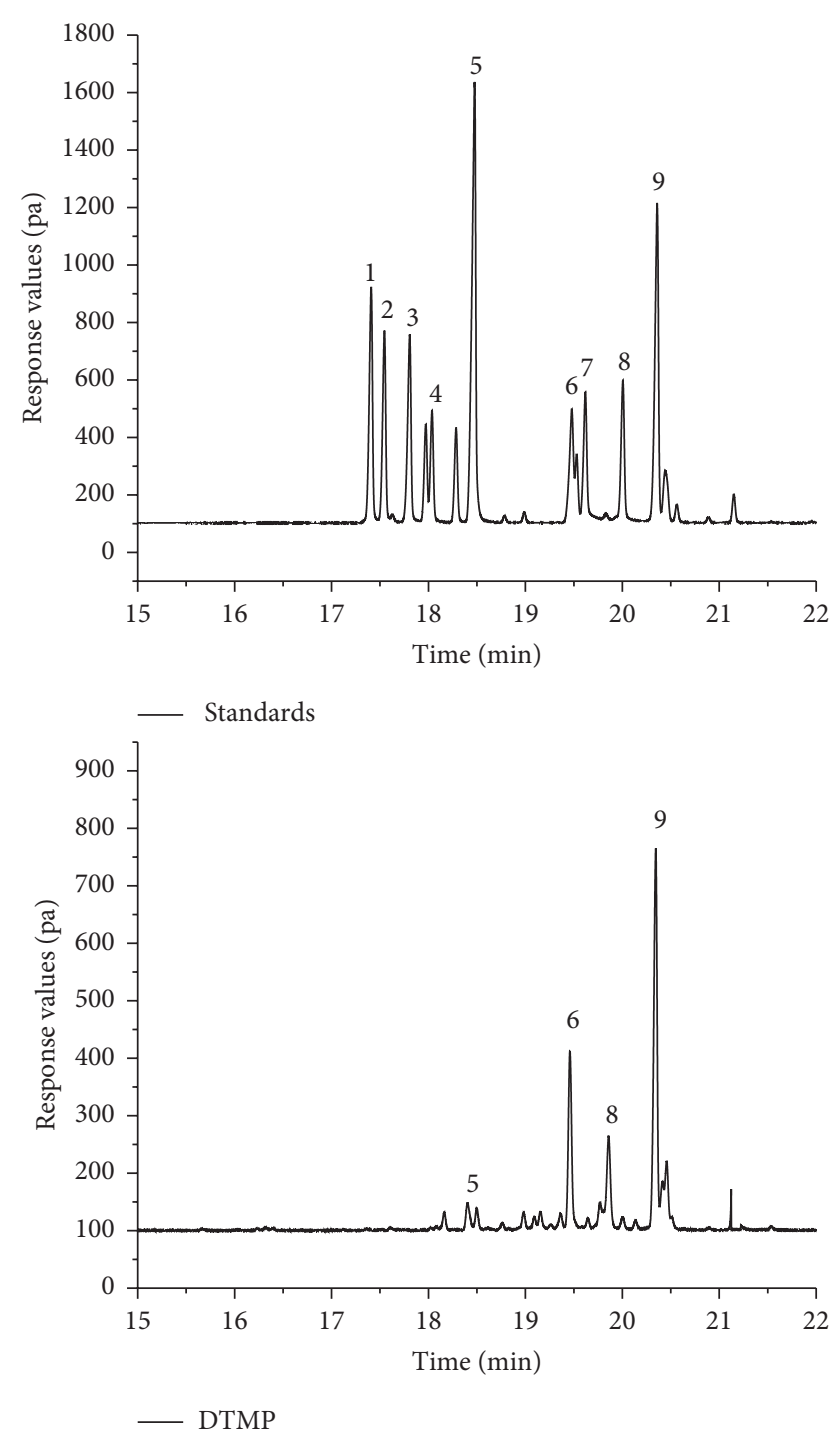

FIgURE 6: The GC-MS chromatograms of 9 standard monosaccharides and component monosaccharides released from DTMP. be seen from the figure, DTMP was mainly composed of mannose, fructose, glucose, and galacturonic acid, of which galacturonic acid was the main component. By calculation, the molar ratio of mannose: fructose: glucose: galacuronic acid in DTMP was $0.8: 14.8: 1.0: 26.32$.

3.4. ${ }^{1} H$ NMR and ${ }^{13} C$ NMIR Spectroscopy. In general, there are several signals in the proton region of ${ }^{1} \mathrm{H}-\mathrm{NMR}$ ( $\delta 4.3-5.9)$, indicating the presence of several sugar residues. In addition, ${ }^{1} \mathrm{H}-\mathrm{NMR}$ signals of the sugar residues in $\alpha$-configuration were greater than $\delta=5.0$, and that of the sugar residues in $\beta$-configuration was less than $\delta 5$.0. The ${ }^{1} \mathrm{H}$ NMR spectrum of the DTMP is shown in Figure 7(a); signal $(\delta 5.20)$ appeared in the heterocephalic proton region, which indicated that DTMP contained a glycoside bond and existed in a configuration pyranose. $\mathrm{H}_{2}-\mathrm{H}_{6}$ signals of sugar residues appeared in the range of $\delta 3.0-4.2$, with serious overlap and difficult to be attributed. In addition, there is a weak signal in the range $\delta 3.2-3.5$, indicating the presence of less $-\mathrm{OCH}_{3}$. In addition, there is a relatively obvious $-\mathrm{CH}$ signal in the range of $\delta 1.0-1.3$, which is classified as fructose signal in methylhexose according to the monosaccharide composition of DTMP [34].

Generally speaking, the proton signal of heterocentric carbon is in the range of $\delta 90-112$, while the proton signal of most a configurational sugar residues is in the range of $\delta$ 90-102. The proton signals of heteroheader carbon of b-configuration sugar residues are located between $\delta 102$ and 112 [35]. The magnetic resonance carbon spectrum of DTMP is shown in Figure 7, and there are three heteroheader carbon signals between $\delta 90$ and 112 (92.05, 93.19, and 95.86), indicating that there are three monosaccharide residues in DTMP. In addition, since the C3 or C5 proton signal of pyronose is less than 80 , the combination of monosaccharide composition and end-group carbon proton signal 93.19. In the ${ }^{13} \mathrm{C} N M R$ spectra, the peaks at C-1 (93.19 ppm), C-2 (75.91 ppm), C-3 (74.09 ppm), C-4 (72.48 ppm), C-5 (71.11 ppm), and C-6 (60.48 ppm) contributed to the backbone chain of DTMP. ${ }^{1} \mathrm{H}$ NMR and ${ }^{13} \mathrm{C}$ NMR spectra showed that DTMP was a polysaccharide with $\alpha$-1,4-glucoside bond. The NMR indicated that the conformation and linkages of DTMP were consistent with the results of GC-MS and FT-IR.

3.5. SEM Analysis. As can be seen from Figure 8, the microstructure of DTMP gels with different concentrations is significantly different. When the concentration is low $(2.0 \%-$ $4.0 \%$ ), the sample presents a flow transition state, and the resulting gel has a uniform microstructure and pore arrangement (Figures $8(\mathrm{a})$ and $8(\mathrm{~b})$ ), which is mainly the result of intermolecular cross-linking of TFP under hydration. With the increase of sample concentration (Figures 8(c)$8(\mathrm{e})$ ), the gel structure changed significantly. The pores became larger, the pore arrangement was irregular, and the three-dimensional honeycomb structure gradually weakened. When the concentration increases to $10 \%$ (Figure $8(\mathrm{e})$ ), the gel state presents solid state, and the microstructure of the gel becomes very dense, presenting 


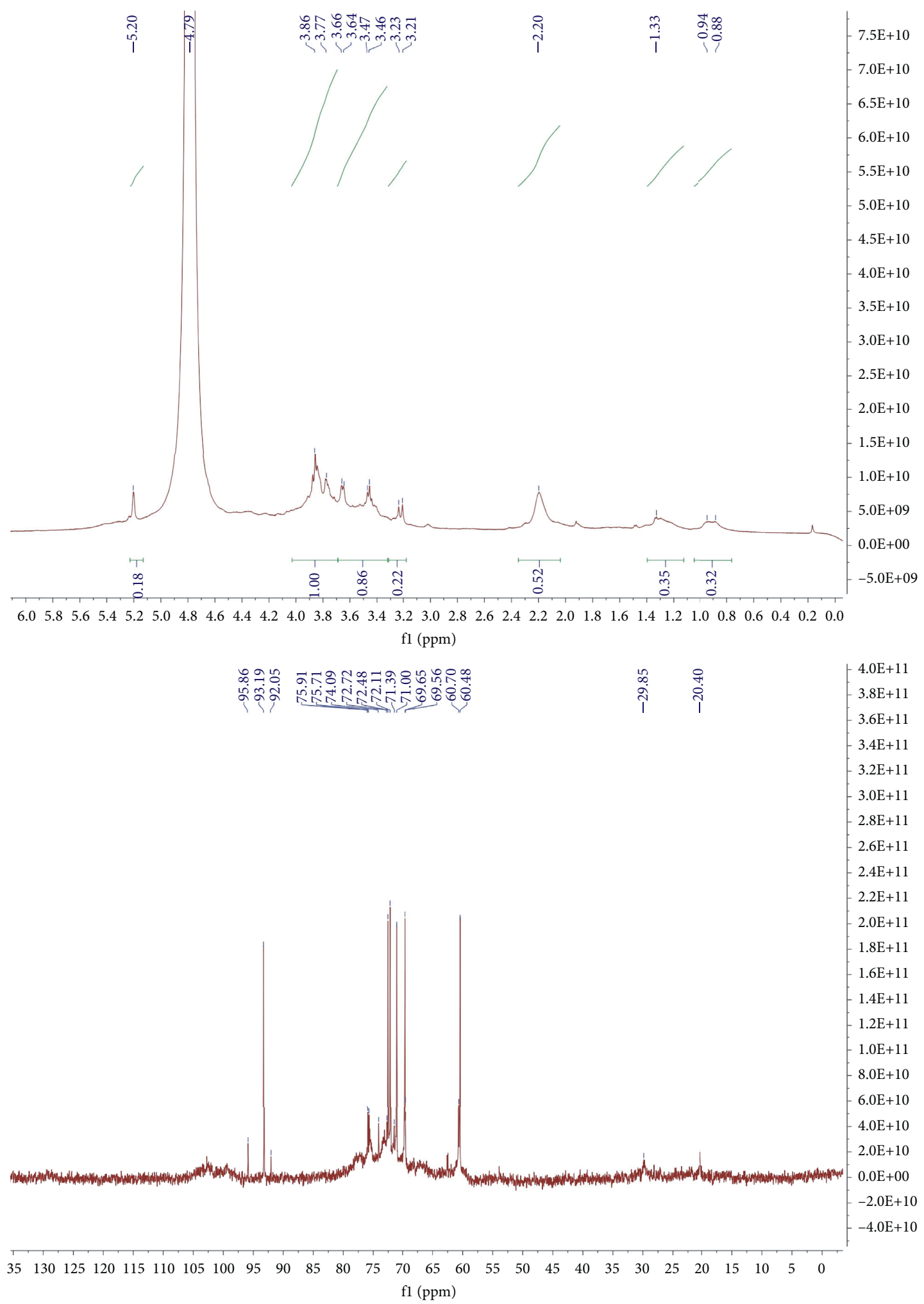

Figure 7: ${ }^{1} \mathrm{H}$ NMR and ${ }^{13} \mathrm{C}$ NMIR spectroscopy of DTMP.

continuous filamentous and flake bonded aggregates. This is consistent with the results of texture analysis and gel strength analysis.
3.6. Strength and Structure Properties of DTMP Gel. As shown in Figure 9, 5 different concentrations of deer polysaccharide gels were placed in test tubes and inverted at 


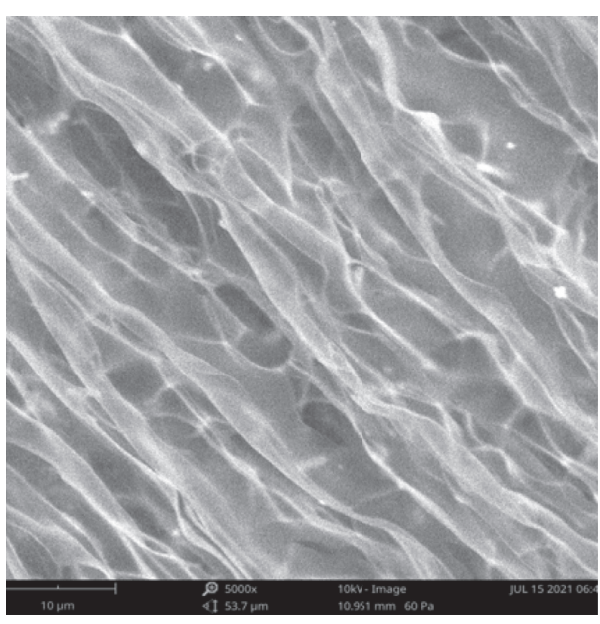

(a)

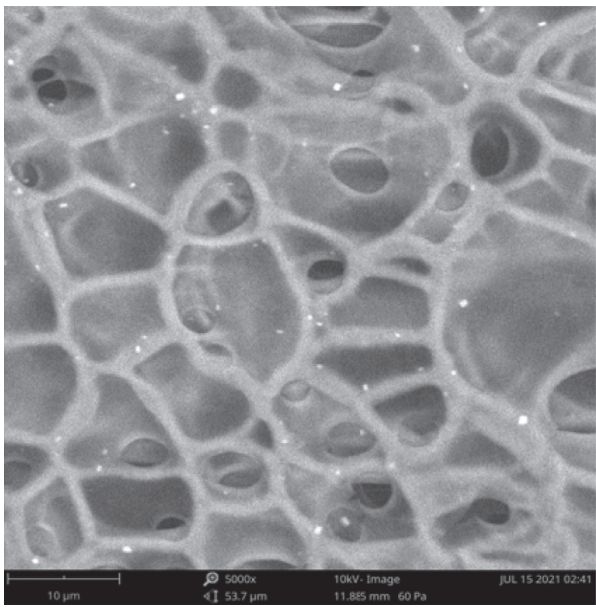

(c)

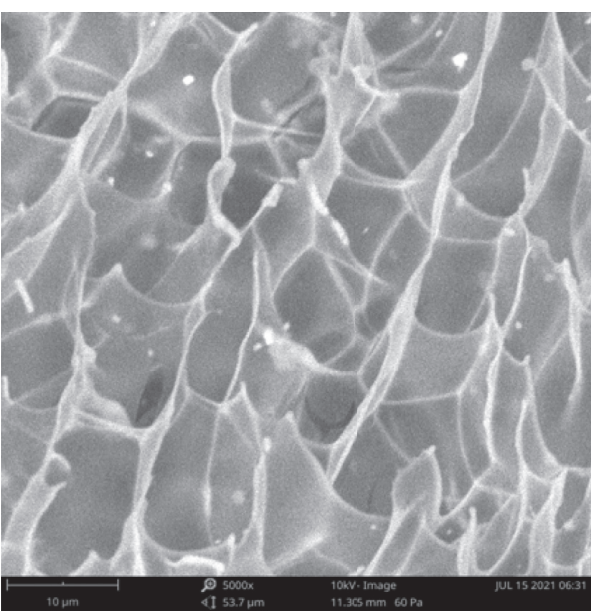

(b)

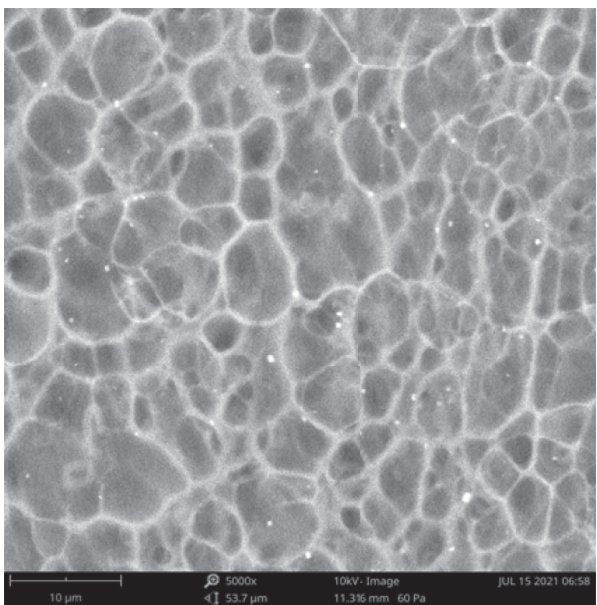

(d)

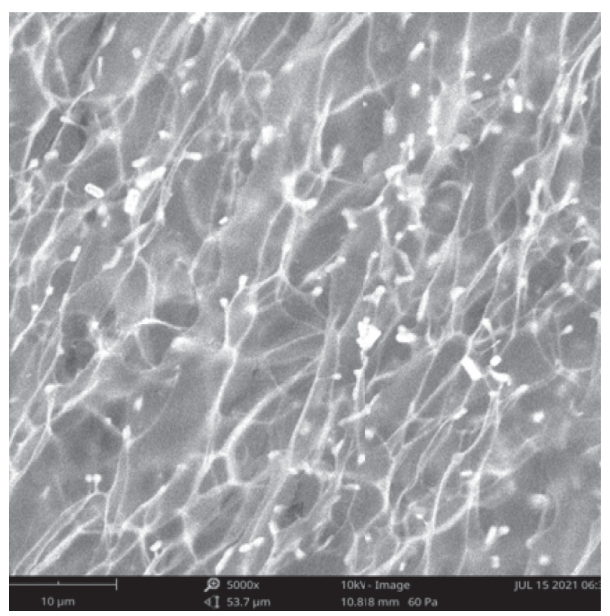

(e)

FIgURE 8: (a-e) SEM of different concentrations of DTMP solutions.

$4^{\circ} \mathrm{C}$ for 24 hours to observe the status of the samples. At low concentrations, the gel has good transparency, sloping surface, and strong mobility. With the increase of the concentration, the transparency and surface inclination of the gel decreased, the fluidity was weakened, and the gel showed good gelation performance. The texture properties of DTMP gels are shown in Table 2. Generally, as the concentration of DTMP increased, the gel strength and rupture strength of the gel increased. However, when the concentration of DTMP was $2.0 \%$ and $10.0 \%$, the elasticity 

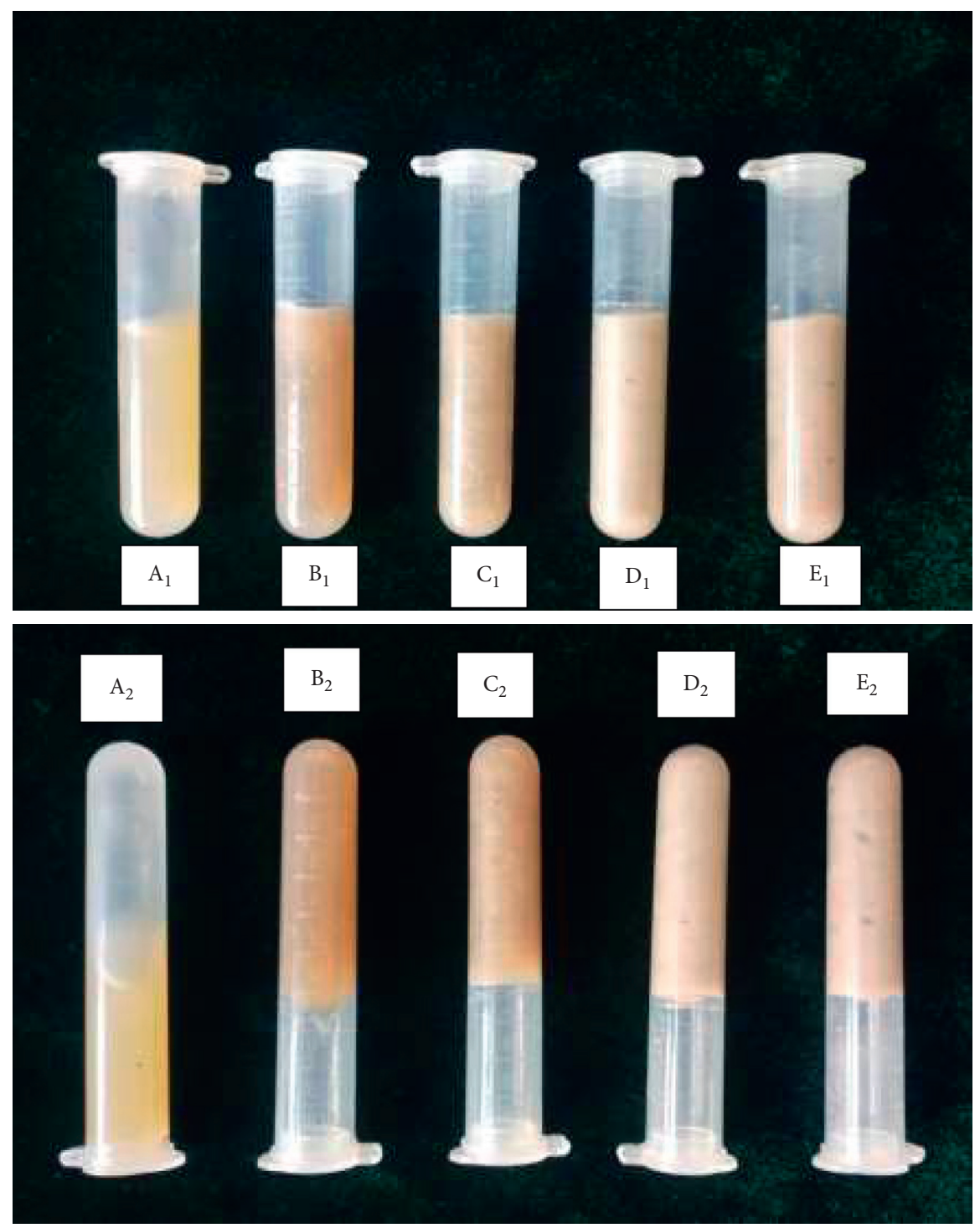

Figure 9: Photos of DTMP solutions at different concentrations (A-E: $2.0 \%-10.0 \%$ ).

TABLE 2: Textural characteristics of DTMP gels at different concentrations.

\begin{tabular}{lccc}
\hline Concentration $(\%)$ & Gel strength $(\mathrm{g})$ & Rupture strength $(\mathrm{g})$ & Rupture distance $(\mathrm{mm})$ \\
\hline 2.0 & $1.390 \pm 0.066^{\mathrm{a}}$ & $1.320 \pm 0.0026^{\mathrm{a}}$ & $0.000 \pm 0.000^{\mathrm{a}}$ \\
4.0 & $6.064 \pm 0.128^{\mathrm{b}}$ & $1.484 \pm 0.127^{\mathrm{a}}$ & $0.000 \pm 0.000^{\mathrm{a}}$ \\
6.0 & $10.870 \pm 0.156^{\mathrm{c}}$ & $10.870 \pm 0.156^{\mathrm{b}}$ & $3.956 \pm 0.046^{\mathrm{b}}$ \\
8.0 & $12.500 \pm 0.233^{\mathrm{d}}$ & $12.543 \pm 0.209^{\mathrm{c}}$ & $3.974 \pm 0.026^{\mathrm{b}}$ \\
10.0 & $14.570 \pm 0.350^{\mathrm{e}}$ & $14.622 \pm 0.367^{\mathrm{d}}$ & $3.980 \pm 0.018^{\mathrm{b}}$ \\
\hline
\end{tabular}

Each value represents the mean \pm standard deviation $(n=3)$. There were significant differences in the values of different letters in the same column $(P<0.05)$.

increased $1.39 \%$ to $14.57 \%$, respectively. These results indicated that there was a synergistic effect between DTMP and water in the system. This synergistic effect was enhanced by the addition of DTMP, which produced a filling effect in the gel. Depending on the hardness and elasticity values, DTMP can be developed into some products, such as frozen and fudge. This means that DTMP could be used as a substitute for some gels in food.

\subsection{Antioxidant Activity Analysis}

3.7.1. DPPH Radical Scavenging Activity. DPPH free radical is a stable lipid free radical. When the free radical scavenger presents, purple gradually fades to a stable yellow, and the degree of depigment is quantitatively related to the number of electrons received [36]. The ability to scavenge DPPH free radicals of vitamin C (VC) and DTMP is shown in Figure 10. 


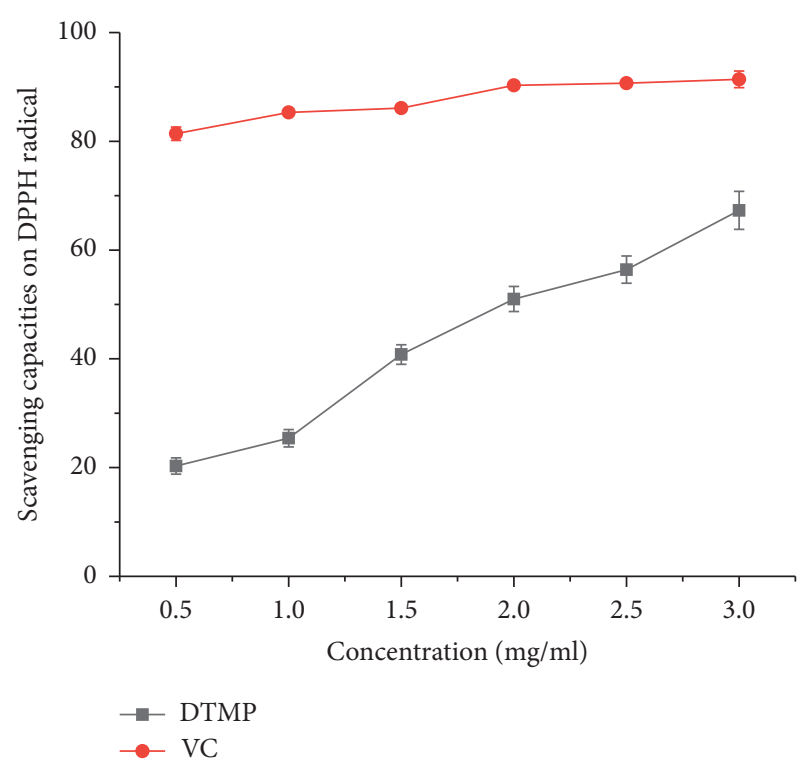

FIGURE 10: In vitro antioxidant results of DTMP (DTMP and VC scavenging DPPH).

When the concentration of VC from 1.0 to $3.0 \mathrm{mg} / \mathrm{mL}$, free radical scavenging rate flattened at (80.25-90.32\%). As shown in Figure 9, with the concentration of $0.5-3.0 \mathrm{mg} / \mathrm{mL}$, the scavenging ability of the samples to DPPH free radicals increased, but relatively weak relative to $\mathrm{VC}$. When the concentration reached $3.0 \mathrm{mg} / \mathrm{mL}$, the DPPH free radical rate of DTMP was $67.53 \pm 0.47 \%$. In addition, the half maximal inhibitory concentration $\left(\mathrm{IC}_{50}\right)$ of DTMP was $2.09 \mathrm{mg} / \mathrm{mL}$, respectively, indicating that the antioxidant effect of DTMP was relatively good.

3.7.2. ABTS Radical Scavenging Activity. ABTS method is widely used for the evaluation of antioxidant capacity of bioactive substances in vitro due to its simple operation and good repeatability [37]. Figure 11 shows the ABTS radical scavenging ability of DTMP. When the VC concentration reached $2.0 \mathrm{mg} / \mathrm{mL}$, the clearance rate reached $95.85 \%$ and then flattened. As shown in Figure 11, as the concentration ranged from 0.5 to $3.0 \mathrm{mg} / \mathrm{mL}$, the scavenging ability of the samples about ABTS radical was increased, but not as good as VC. In addition, the $\mathrm{IC}_{50}$ values of DTMP were $3.81 \mathrm{mg}$ / $\mathrm{mL}$, indicating that the antioxidant effect of DTMP had a certain antioxidant effect.

3.7.3. OH Scavenging Activity. Hydroxyl free radical (-OH) is the most reactive free radical in ROS, which may directly or indirectly cause tissue damage, induce a variety of human diseases including cancer, and promote aging [38]. As shown in Figure 12, when the DTMP concentrations of $0.5-3.0 \mathrm{mg} /$ $\mathrm{mL}$, the scavenging ability of all samples to hydroxyl free radicals increased with the increase of DTMP concentration, but all of them were lower than VC. In addition, the $\mathrm{IC}_{50}$ of DTMP was $3.49 \mathrm{mg} / \mathrm{mL}$, indicating that the $-\mathrm{OH}$ free scavenging effect of DTMP was weaker than DPPH free radical scavenging ability.

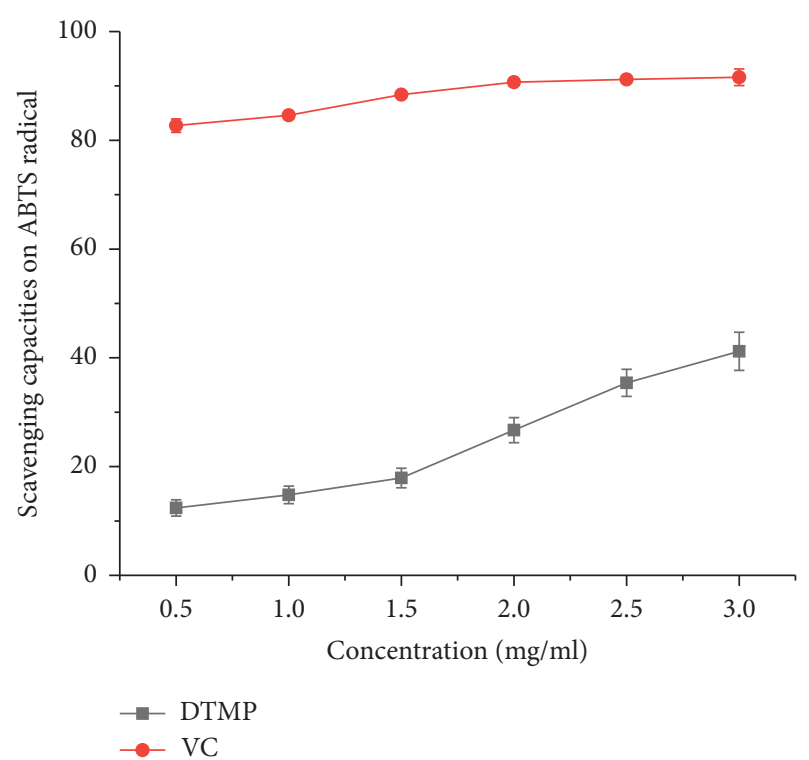

FIgURE 11: In vitro antioxidant results of DTMP (DTMP and VC scavenging ABTS).

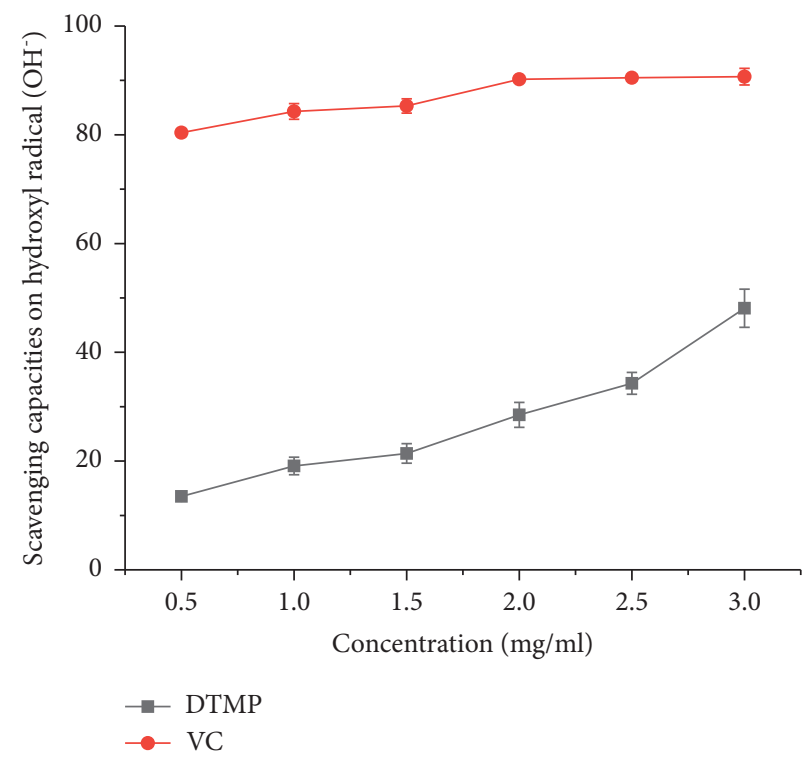

FIGURE 12: In vitro antioxidant results of DTMP (DTMP and VC scavenging. $\mathrm{OH})$.

3.7.4. $\mathrm{O}^{2-}$ Scavenging Activity. The $\mathrm{O}^{2-}$ is a kind of ROS anionic free radical in the human body, which leads to lipid peroxidation in vivo and accelerates body aging. Figure 13 shows the $\mathrm{O}^{2-}$ scavenging ability of DTMP and VC. At concentrations from 0.5 to $3.0 \mathrm{mg} / \mathrm{mL}$, DTMP showed a dependence on concentrations. At $3.0 \mathrm{mg} / \mathrm{mL}$, DTMP were $52.76 \pm 0.48 \%$, both were lower than for VC. The ability of polysaccharides scavenge superoxide anionradicals is associated with the quantity of active phenolic and alcohol hydroxyl groups in the molecule [39]. In addition, the $\mathrm{IC}_{50}$ value of DTMP was $3.07 \mathrm{mg} / \mathrm{mL}$, respectively, indicating 


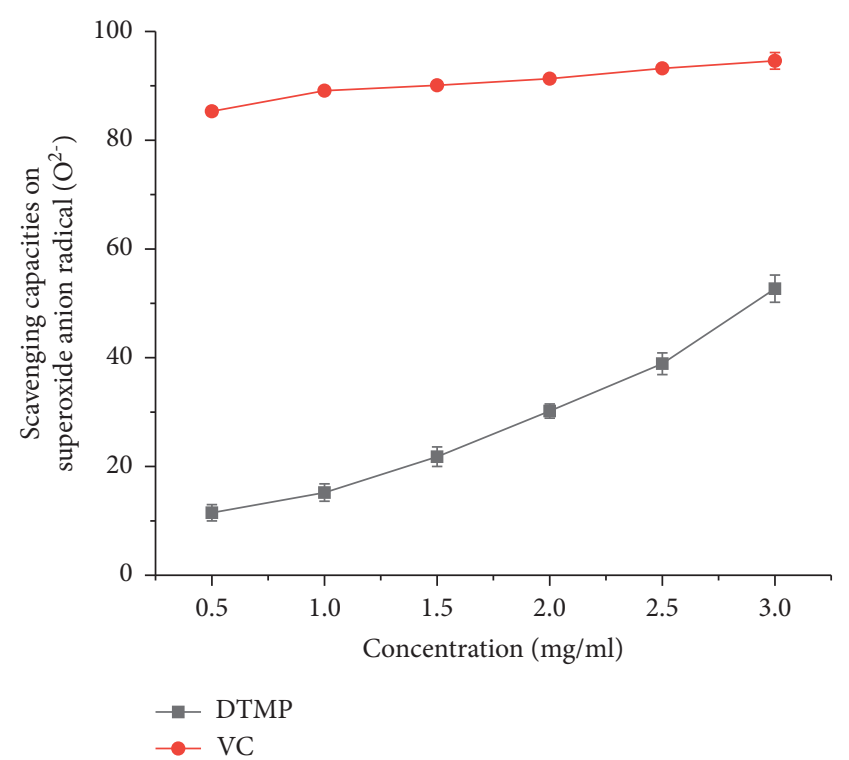

FIGURE 13: In vitro antioxidant results of DTMP (DTMP and VC scavenging $\mathrm{O}^{2-}$ ).

that the -OH free scavenging effect of DTMP was just below DPPH free radical scavenging ability.

\section{Conclusion}

In this study, DTMP was obtained by water extraction and alcohol precipitation. The results showed that DTMP is mainly composed of mannose, fructose, glucose, and galacturonic acid, of which galacturonic acid is the main component. By calculation, the molar ratio of mannose: fructose : glucose : galacuronic acid in DTMP is $0.8: 14.8$ : $1.0: 26.32$. And through the $\alpha-1,4$-glycosidic bond and a certain amount of $\alpha$-1.2-glycosidic bond, $\alpha$-1,6-glycosidic bond, and $\alpha-1,5$-glycosidic bond. The rheological results showed the following: DTMP solution showed a shearthinning (pseudoplastic) behaviour, and its pseudoplasticity was more obvious at a concentration of $2 \%$. The power law model was used to evaluate the viscosity curves of DTMP, and its viscosity and consistency indices both increased as the concentration increased, whereas both indices decreased as the concentration decreased. The viscosity of the polysaccharide solution changed as the $\mathrm{pH}$ and temperature changed: the polysaccharide solutions had a higher viscosity at $\mathrm{pH}=10$ and $35^{\circ} \mathrm{C}$. DTEP had good thermal stability. Viscoelastic analyses showed gel-like behaviour, with $\mathrm{G}^{\prime}$ always higher than $\mathrm{G}^{\prime \prime}$. The gel strength and rupture strength enhanced with the increase of concentration $2 \%-10 \%(\mathrm{~W} / \mathrm{V})$. Additionally, the antioxidant experiments of the crude polysaccharide showed that the crude polysaccharide had good antioxidant activity, and there was an obvious dose-effect relationship between its activity and concentration in the low concentration range. This research provides a solid foundation for the in-depth research and industrial application of polysaccharide from the deer tripe mushroom.

\section{Data Availability}

The data used to support the findings of this study are available from the corresponding author upon request.

\section{Conflicts of Interest}

All authors declare that there are no conflicts of interest.

\section{Authors' Contributions}

All authors read and approved the final manuscript.

\section{Acknowledgments}

This study was financially supported by the Key Projects of the National Research and Development Program of China (Grant no. 2018YFD0400204).

\section{References}

[1] S. D. Wangkheirakpam, D. D. Joshi, G. D. Leishangthem, D. Biswas, and L. Deb, "Hepatoprotective effect of Auricularia delicata (Agaricomycetes) from India in rats: biochemical and histopathological studies and antimicrobial activity," International Journal of Medicinal Mushrooms, vol. 20, no. 3, pp. 213-225, 2018.

[2] Y. LI, Chinese Black Fungus, Changchun Press, Changchun, China, 2001.

[3] C. Zyab, C. Zlab, C. Clab, C. Jwab, C. Cmab, and C. Wkab, "Immunomodulatory effects of polysaccharides from edible fungus: a review," Food Science and Human Wellness, vol. 10, no. 4, pp. 393-400, 2021.

[4] A. Bandara, "A review of the polysaccharide, protein and selected nutrient content of Auricularia, and their potential pharmacological value," Mycosphere, vol. 10, no. 1, pp. 579-607, 2019.

[5] D. Wang, X. Jiang, S. Teng et al., "The antidiabetic and antinephritic activities of auricularia cornea (an albino mutant strain) via modulation of oxidative stress in the $\mathrm{db} / \mathrm{db}$ mice," Frontiers in Immunology, vol. 10, p. 1039, 2019.

[6] H. Xiang, D. X. Sun-Waterhousea, and C. Cui, "Hypoglycemic polysaccharides from Auricularia auricula and Auricularia polytricha inhibit oxidative stress, NF-KB signaling and proinflammatory cytokine production in streptozotocin-induced diabetic mice," Food Science and Human Wellness, vol. 10, no. 4, pp. 87-93, 2021.

[7] J. Qiu, H. Zhang, and Z. Wang, "Ultrasonic degradation ofPolysaccharides from Auricularia auricula and the antioxidant activity of their degradation products," LebensmittelWissenschaft \& Technologie, vol. 113, Article ID 108266, 2019.

[8] Y. Zhang, Y. Zeng, Y. Men, J. Zhang, H. Liu, and Y. Sun, "Structural characterization and immunomodulatory activity of exopolysaccharides from submerged culture of Auricularia auricula-judae," International Journal of Biological Macromolecules, vol. 115, pp. 978-984, 2018.

[9] Y. Zhang, D. Wang, Y. Chen et al., "Healthy function and high valued utilization of edible fungi," Food Science and Human Wellness, vol. 10, no. 4, pp. 408-420, 2021.

[10] M. E. E. Franklin, H. A. Pushpadass, and B. Kumar, "Physicochemical thermal, pasting and microstructural characterization of commercial Curcuma angustifolia starch," Food Hydrocolloids, vol. 67, pp. 27-36, 2016. 
[11] C. Rolin, "Commercial pectin preparations," in Pectins and Their Manipulation, G. B. Seymour and J. P. Knox, Eds., pp. 222-241, CRC Press/Blackwell Publishing, Oxford, UK, 2002.

[12] J.-L. Xu, J.-C. Zhang, Y. Liu, H.-J. Sun, and J.-H. Wang, "Rheological properties of a polysaccharide from floral mushrooms cultivated in Huangshan Mountain," Carbohydrate Polymers, vol. 139, pp. 43-49, 2016.

[13] F. Danalache, P. Mata, M. Moldão-Martins, and V. D. Alves, "Novel mango bars using gellan gum as gelling agent: rheological and microstructural studies," Lebensmittel-Wissenschaft und-Technologie- Food Science and Technology, vol. 62, no. 1 , pp. 576-583, 2015.

[14] H. Abreu, F. F. Simas, F. R. Smiderle et al., "Gelling functional property, anti-inflammatory and antinociceptive bioactivities of $\beta$-D-glucan from the edible mushroom Pholiota nameko," International Journal of Biological Macromolecules, vol. 122, pp. 1128-1135, 2019.

[15] H. Bao, S. You, L. Cao, R. Zhou, Q. Wang, and S. W. Cui, "Chemical and rheological properties of polysaccharides from fruit body of Auricularia auricular-judae," Food Hydrocolloids, vol. 57, pp. 30-37, 2016.

[16] K. Zhu, X. Chen, D. Yu, Y. He, and G. Song, "Preparation and characterisation of a novel hydrogel based on Auricularia polytricha $\beta$-glucan and its bio-release property for vitamin B12 delivery," Journal of the Science of Food and Agriculture, vol. 98, no. 7, pp. 2617-2623, 2018.

[17] Z.-W. Sun, L.-X. Zhang, B. Zhang, and T.-G. Niu, "Structural characterisation and antioxidant properties of polysaccharides from the fruiting bodies of Russula virescens," Food Chemistry, vol. 118, no. 3, pp. 675-680, 2010.

[18] X. Zhang, X. Kong, Y. Hao, X. Zhang, and Z. Zhu, "Chemical structure and inhibition on $\alpha$-glucosidase of polysaccharide with alkaline-extracted from glycyrrhiza inflata residue," International Journal of Biological Macromolecules, vol. 147, pp. 1125-1135, 2020.

[19] H. W. Qiu, Z. P. Shu, Q. X. Bing, X. Na, and X. K. Hai, "Structural characterization and antioxidant activities of polysaccharides from citrus aurantium 1," International Journal of Biological Macromolecules, vol. 67, no. 6, pp. 112123, 2014.

[20] W. Yang, J. Wu, W. Liu et al., "Structural characterization, antioxidant and hypolipidemic activity of Grifola frondosa polysaccharides in novel submerged cultivation," Food Bioscience, vol. 42, Article ID 101187, 2021.

[21] J. Zhang, L. Zhou, L. Cui, Z. Liu, J. Wei, and W. Kang, "Antioxidant and $\alpha$-glucosidase inhibitiory activity of Cercis chinensis flowers," Food Science and Human Wellness, vol. 9, no. 4, pp. 313-319, 2020.

[22] A. F. Ahmed, F. A. K. Attia, Z. Liu, C. Li, J. Wei, and W. Kang, "Antioxidant activity and total phenolic content of essential oils and extracts of sweet basil (Ocimum basilicum L.) plants," Food Science and Human Wellness, vol. 8, no. 3, pp. 299-305, 2019.

[23] M. L. C. Gonzaga, T. M. F. Menezes, L. M. Rebêlo, J. R. R. de Souza, N. M. P. S. Ricardo, and S. d. A. Soares, "Agaricus brasiliensis mushroom betaglucans solutions: physicochemical properties and griseofulvin solubilization by self-assembly micro-nano particles formation," Bioactive Carbohydrates and Dietary Fibre, vol. 4, no. 2, pp. 144-154, 2014.

[24] H. Rohm, B. Böhme, and J. Skorka, “The impact of grinding intensity on particle properties and rheology of dark chocolate," Lebensmittel-Wissenschaft \& Technologie, vol. 92, pp. 564-568, 2018.

[25] A. D. Saputro, D. Van de Walle, S. Kadivar, M. A. Mensah, J. Van Durme, and K. Dewettinck, "Feasibility of a small-scale production system approach for palm sugar sweetened dark chocolate," European Food Research and Technology, vol. 243, no. 6, pp. 955-967, 2017.

[26] Y. D. Zhang, Y. Q. Du, H. L. Zhang et al., "Structural and rheological properties of a gel polysaccharide from umbilicaria esculenta grown in huangshan mountain," Current Topics in Nutraceutical Research, vol. 16, pp. 65-74, 2017.

[27] S. B. Nair, A. N. Jyothi, M. S. Sajeev, and R. Misra, "Rheological, mechanical and moisture sorption characteristics of cassava starch-Konjac glucomannan blend films," Starch Stärke, vol. 63, no. 11, pp. 728-739, 2011.

[28] R. Moorehouse, M. D. Walkinshaw, and S. Arnott, "Xanthan gum-molecular conformation and interactions," in Extracellular Microbial Polysaccharides, P. Sanford and A. Laskin, Eds., pp. 90-102, ACS Publications, Washington, DC, USA, 1977.

[29] G. Chen, K. Chen, R. Zhang, X. Chen, P. Hu, and J. Kan, "Polysaccharides from bamboo shoots processing by-products: new insight into extraction and characterization," Food Chemistry, vol. 245, pp. 1113-1123, 2018.

[30] H. Kaiwei, Y. Li, S. Tao, G. Wei, Y. Huang, and D. Chen, "Purification, characterization and biological activity of polysaccharides from Dendrobiumofficinale," Molecules, vol. 21, no. 6, 2016.

[31] H. Tao-Bin, Y. P. Huang, L. Yang, T. T. Liu, W. Y. Gong, and X. J. Wang, "Structural characterization and immunomodulating activity of polysaccharide from Dendrobium officinale," International Journal of Biological Macromolecules, vol. 83, pp. 34-41, 2016.

[32] L. He, X. Yan, J. Liang et al., "Comparison of different extraction methods for polysaccharides from Dendrobium officinale stem," Carbohydrate Polymers, vol. 198, pp. 101-108, 2018.

[33] W. Wei, L. Feng, W.-R. Bao et al., "Structure characterization and immunomodulating effects of polysaccharides isolated from Dendrobium officinale," Journal of Agricultural and Food Chemistry, vol. 64, no. 4, pp. 881-889, 2016.

[34] D. Suvakanta, M. P. Narsimha, D. Pulak, C. Joshabir, and D. Biswajit, "Optimization and characterization of purified polysaccharide from Musa sapientum L. as a pharmaceutical excipient," Food Chemistry, vol. 149, pp. 76-83, 2014.

[35] Y. Tamaki, T. Konishi, M. Fukuta, and M. Tako, "Isolation and structural characterisation of pectin from endocarp of Citrus depressa," Food Chemistry, vol. 107, no. 1, pp. 352-361, 2008.

[36] X. Du, H. Mu, S. Zhou, Y. Zhang, and X. Zhu, "Chemical analysis and antioxidant activity of polysaccharides extracted from Inonotus obliquus sclerotia," International Journal of Biological Macromolecules, vol. 62, no. 11, pp. 691-696, 2013.

[37] M. B. Amao, "Some methodological problems in the determination of antioxidant activity using chromogen radicals: a practical case," Trends in Food Science \& Technology, vol. 11, pp. 419-421, 2000.

[38] H. L. Huang, Z. G. Wang, and B. Z. Fu, "Study on antioxidant effects and medchanism of extracts from Jussiaea repens on edible oil and fat," Food Science, vol. 29, pp. 880-882, 2008.

[39] Z. Guo, R. Xing, S. Liu et al., "The synthesis and antioxidant activity of the Schiff bases of chitosan and carboxymethyl chitosan," Bioorganic \& Medicinal Chemistry Letters, vol. 15, no. 20, pp. 4600-4603, 2005. 